\title{
Solution for Organ Preservation Dosage Form
}

National Cancer Institute

\section{Source}

National Cancer Institute. Solution for Organ Preservation Dosage Form. NCI Thesaurus.

Code C149925.

Liquid sterile preparation consisting of an aqueous solution of electrolytes typically at a concentration close to the intracellular electrolyte composition, intended for storage, protection and/or perfusion of mammalian body organs that are in particular destined for transplantation. 